\title{
Machine Design Experiments Using Gears to Foster Discovery Learning
}

\section{Mr. Jonathon E. Slightam, Marquette University Mechanical Engineering Department}

Jonathon E. Slightam received his B.S degree in mechanical engineering and M.Sc. in engineering from the Milwaukee School of Engineering in 2012 and 2014, respectively. Jonathon is currently a PhD student in mechanical engineering at Marquette University, Milwaukee, WI. From 2009 to 2014, he was a research assistant in the Rapid Prototyping Research laboratory at the Milwaukee School of Engineering. In 2013 he was an engineering intern at Parker Hannifin's hydraulic cartridge systems group located in Lincolnshire, IL. Presently, he is a teaching assistant for the mechanical engineering department at Marquette University. His interests are in the modeling, design, and control of flexible fluidic actuators, humanoid robots, and design of efficient mobile robots using additive manufacturing.

\section{Dr. Mark L. Nagurka, Marquette University}

MARK NAGURKA, Ph.D. is an Associate Professor of Mechanical and Biomedical Engineering at Marquette University. He received his B.S. and M.S. in Mechanical Engineering and Applied Mechanics from the U.of Pennsylvania and a Ph.D. in Mechanical Engineering from M.I.T. He taught at Carnegie Mellon before joining Marquette University. His professional interests are in the design of mechanical and electromechanical systems and in engineering education. He is a registered Professional Engineer in Wisconsin and Pennsylvania, a Fellow of the American Society of Mechanical Engineers (ASME), and a former Fulbright Scholar. 


\title{
Machine Design Experiments Using Gears to Foster Discovery Learning
}

\begin{abstract}
Experiments were designed to provide engineering students with opportunities for discovery learning experiences with mechanical systems using gears. This paper describes the experiments, which present students with a range of practical challenges requiring them to analyze, measure, design, and fabricate gears and gear systems. Activities in the experiments include: (1) identifying gear types (spur, helical, bevel, etc.) and appropriate applications (transmissions, differentials, gearmotors, etc.). (2) Disassembling and reassembling an automotive HVAC baffle subassembly (with measurement of train ratios, and design and manufacturing questions related to its gears). (3) Disassembling and reassembling a kitchen mixer (with design and manufacturing questions related to its gears). (4) Designing the gear mechanism for driving the hands of a clock given an input speed, fabricating the gears of the clock via rapid prototyping (3D printing), assembling the clock, and testing the timing accuracy.
\end{abstract}

\section{Introduction}

The typical undergraduate engineering student will encounter the topic of gears in several courses. Early exposure may be in a physics course or in a first dynamics course, where gear pairs are presented as a means to change speed ratios and torque ratios. They are used for mechanical advantage, to achieve desired speed, or to change rotational direction. Although the focus is usually on kinematics, since gears have inertia they store kinetic energy and are part of the dynamic equations of motion of mechanisms and machines. For mechanical engineering students, gears are studied in courses such as 'kinematics and dynamics of mechanisms' and 'machine design', where the nomenclature and design equations are developed for various types of gears. There may be exposure to real gears in a mechanical engineering laboratory; more often, students may see gears passed around in class and as part of demonstrations. Hands on pragmatic exposure to gears and gear systems may improve student theoretical comprehension and more realistically prepare students for industrial careers.

\section{Discovery Learning}

The term "discovery learning" covers a variety of instructional techniques, such as active, cooperative, collaborative, project-based, and inductive learning. In these student-centered pedagogical methods, the focus of activity is shifted from the teacher to the learner. The student is not provided with an exact answer or a specified approach but with the materials and resources that can be used to find the answer independently. In the context of a laboratory setting, discovery learning takes place when a challenge is posed and the experimental resources are available for more open-ended investigation, without a 'follow-the-recipe' type manual or detailed instruction. In solving the challenge the student is actively engaged in an investigation that draws on prior experience and knowledge as well as new knowledge. By interacting with, exploring, and manipulating physical components and systems, the student wrestles with the challenge and performs the necessary experiments to gain insight and understanding. Discovery learning methods have been studied in detail and their advantages for promoting and enhancing learning have been well documented. ${ }^{1-6}$ 


\section{Design of Machine Elements Course}

In the College of Engineering at Marquette University the "Design of Machine Elements" course is a required 4-credit course for junior/senior mechanical engineering students. The course is also a technical elective for biomedical engineering students. The course consists of 3 hours of lecture (two 75 minute classes or three 55 minute classes) and 2 hours of laboratory work each week. Laboratory experiments that promote discovery learning have been created for this course. A description of the Machine Design Laboratory and details of earlier experiments were reported at previous ASEE Conferences. 7,8

Each year new laboratory activities in the "Design of Machine Elements" course are introduced and previous experiments are re-evaluated, modified, and refreshed. This development process improves the laboratory experiences for students. Laboratory activities are designed to foster discovery learning, and promote the use of hand tools for disassembly and re-assembly of real-world mechanical systems. In the past, some experiments that addressed gear applications were conducted. The desire for more meaningful experiences motivated the current work.

In the Machine Design Laboratory there are examples of mechanical gear systems used in transmissions, differentials, appliances, and other machines. They include a Buell Blast motorcycle engine assembly, an RV leveler, a Rexnord gearbox, a $90^{\circ}$ bevel gearbox, Bodine Electric gearmotors, Milwaukee Electric Tool impact wrenches and Sawzalls, and a truck differential. Students are encouraged to investigate the operation of these systems. Several have cutaways and can be operated by hand cranks giving students direct experience with the fundamentals of gears and the design of gear assemblies.

\section{Discovery Learning Experiments with Gears}

This paper describes four experiments in which students analyze and design gears in mechanical systems. Each experiment has been designed to challenge students in meaningful ways. Each can be conducted in a 20-30 minute session, such that all four experiments can be completed in a 2 hour laboratory section with 2-3 students working in a team.

\section{Experiment 1: Gear Identification and Applications}

In this experiment (see Figure 1) students are asked to identify different gear types, such as spur, helical, bevel, worm, planetary, etc., and then suggest appropriate applications for these in combination. Students sketch free-body diagrams of meshing gears that depict the forces acting on gear teeth. After examining gears in several different systems (automotive transmissions and differentials, gearboxes, drills, and gearmotors), students are asked to draw insights about the gears used. They are also asked to select gears from catalogs to satisfy a design requirement. The goal is for students to become familiar with different types of gears used in mechanical systems and gain an appreciation for the importance of proper gear choice in making design decisions. 

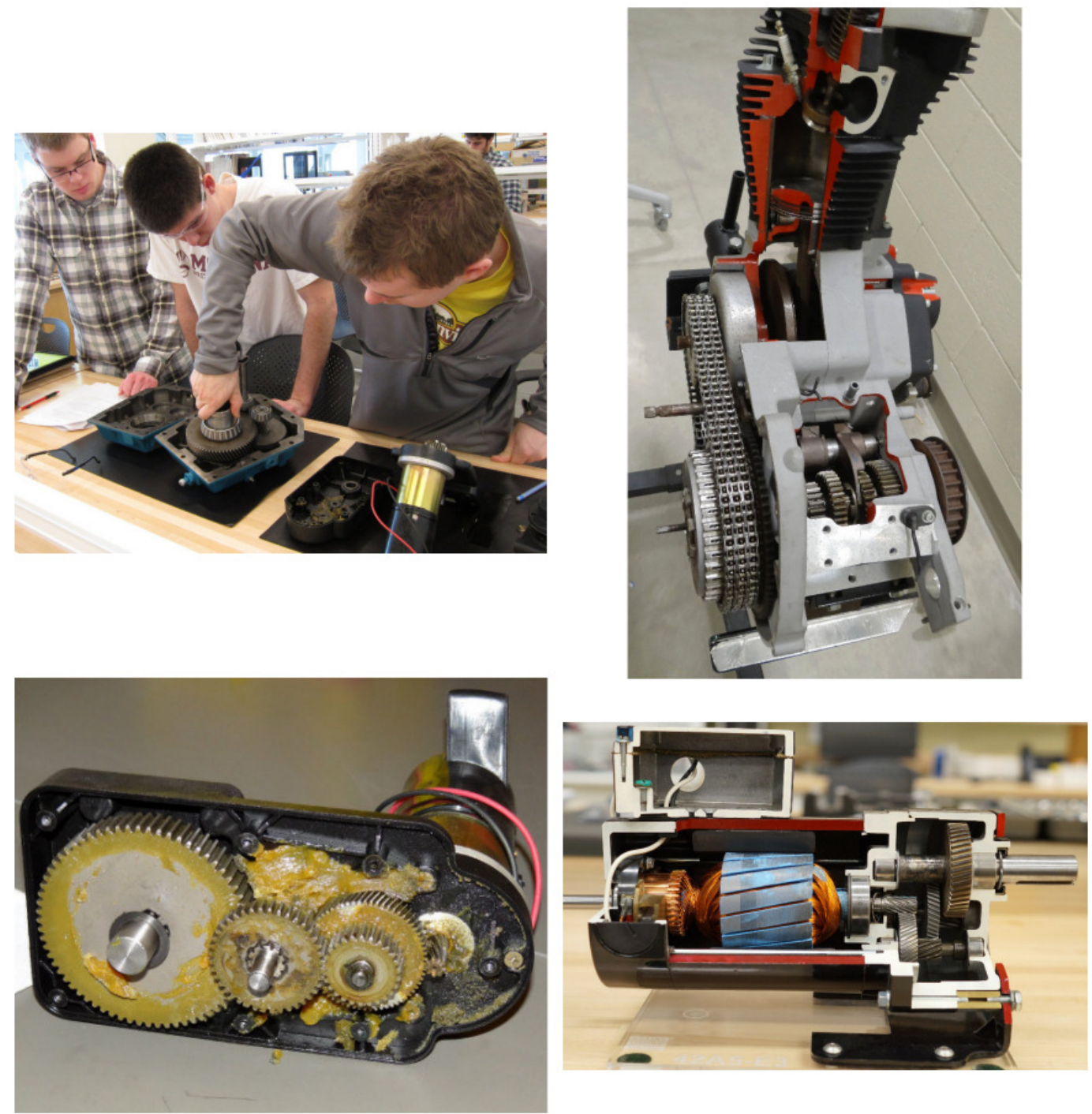

Figure 1: Gear identification and applications.

\section{Experiment 2: Automotive HVAC Baffle Operation and Gear Design}

In this experiment (see Figure 2) students are presented with an automotive HVAC baffle subassembly (a gearmotor used in the 2002-2005 Dodge Stratus that was available as surplus). They are asked to measure the output speed of the unit, then disassemble the unit, count teeth of all gears in the four meshes between the input and output, and calculate the DC motor speed driving the input gear. Using a laser tachometer, students then measure the shaft speed of the motor and explain discrepancies in their prediction. There are several challenges in this experiment. They must figure out how to measure output speed, how to disassemble the unit, classify whether the worm of the worm gear is single or multi thread, determine the train ratio, answer design and manufacturing questions about the unit, and reassemble the unit. 

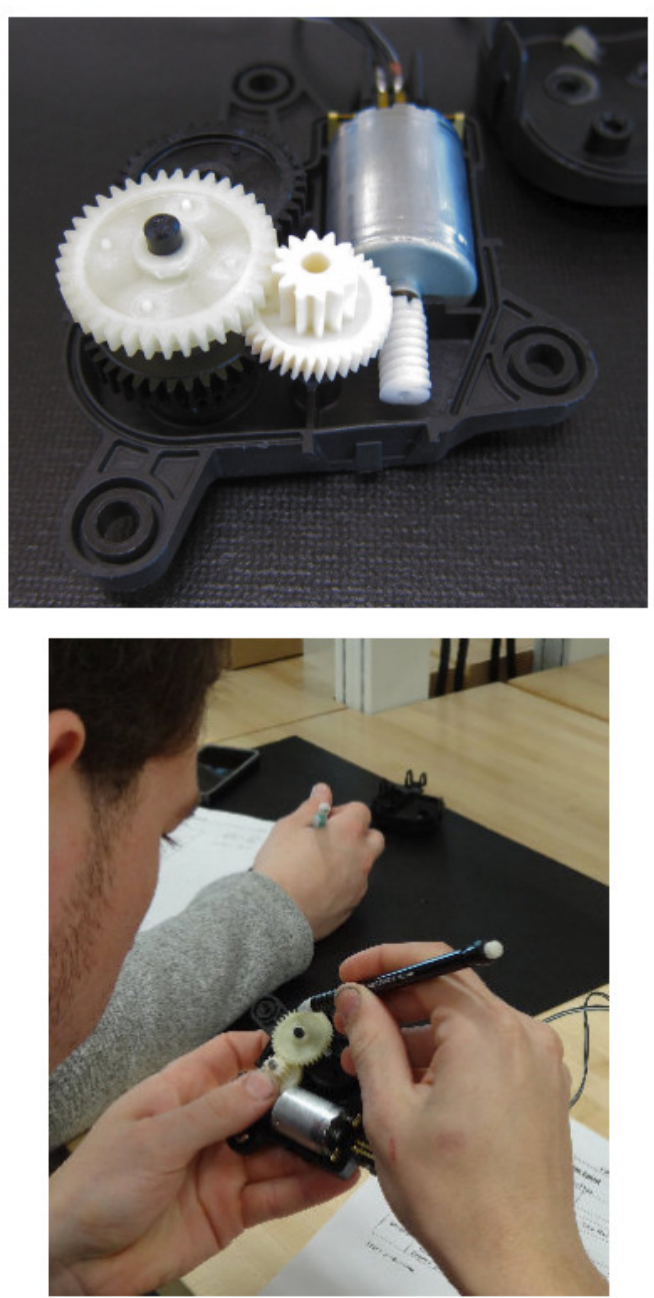
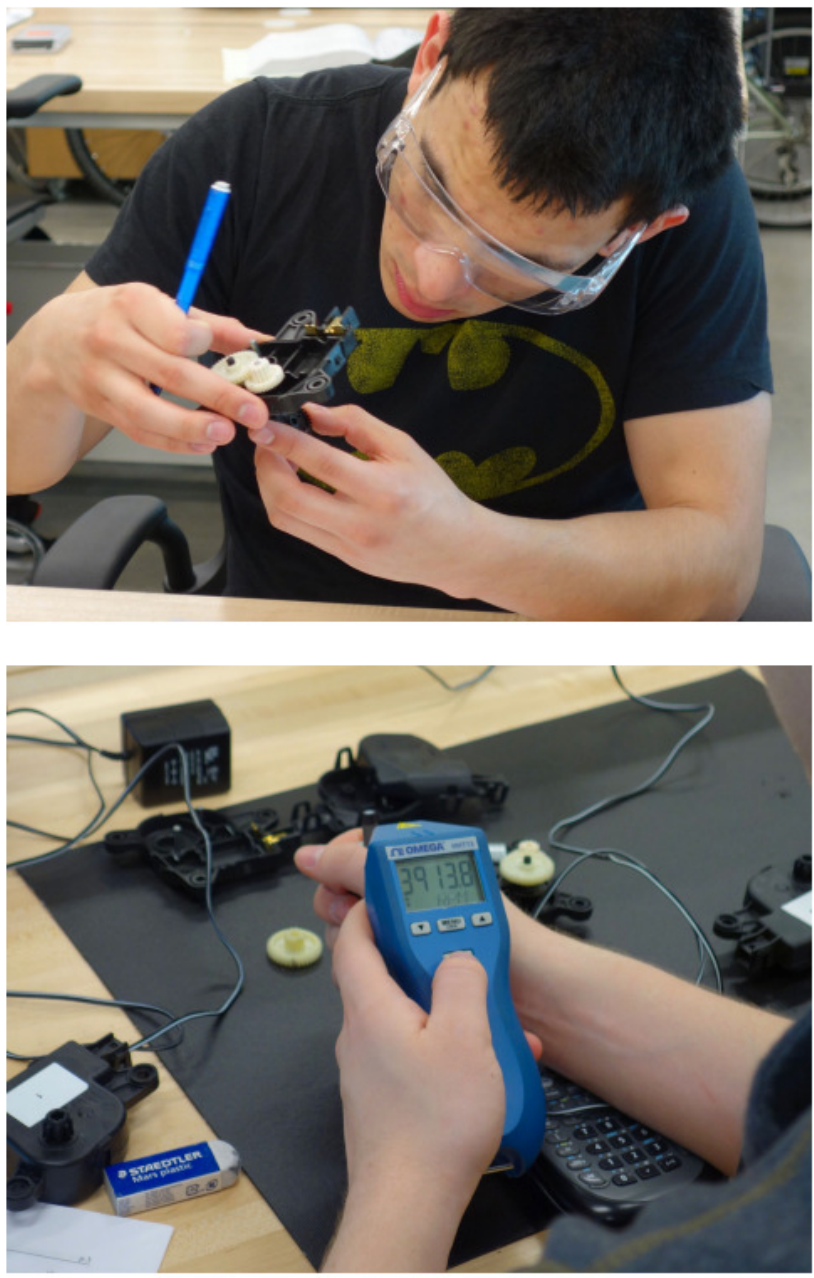

Figure 2: Automotive HVAC baffle operation and gear design.

\section{Experiment 3: Kitchen Mixer Operation and Gear Design}

In this experiment (see Figure 3) students are asked to disassemble a KitchenAid mixer, investigate the gears used, and then reassemble the mixer. A pre-cleaned mixer is available for detailed examination of the inner gear assemblies. Disassembly requires a number of tools: punch, hammer, and flat-head/slot and square/Robertson screwdrivers. Students are asked to identify the drive gear, gear-mesh groupings, gear types, etc. Several questions are posed: What is the purpose of the nylon gear and why is it made of nylon? Why are worm and worm gears used? What is the purpose of the bevel pinion and center gear assembly? How many degrees of freedom does the planetary gear system have and how does the manufacturer accomplish this? What is the purpose of the food-safe grease? Students are then asked to reassemble the mixer, and to design an alternate gear system that would offer the main mixer features. 

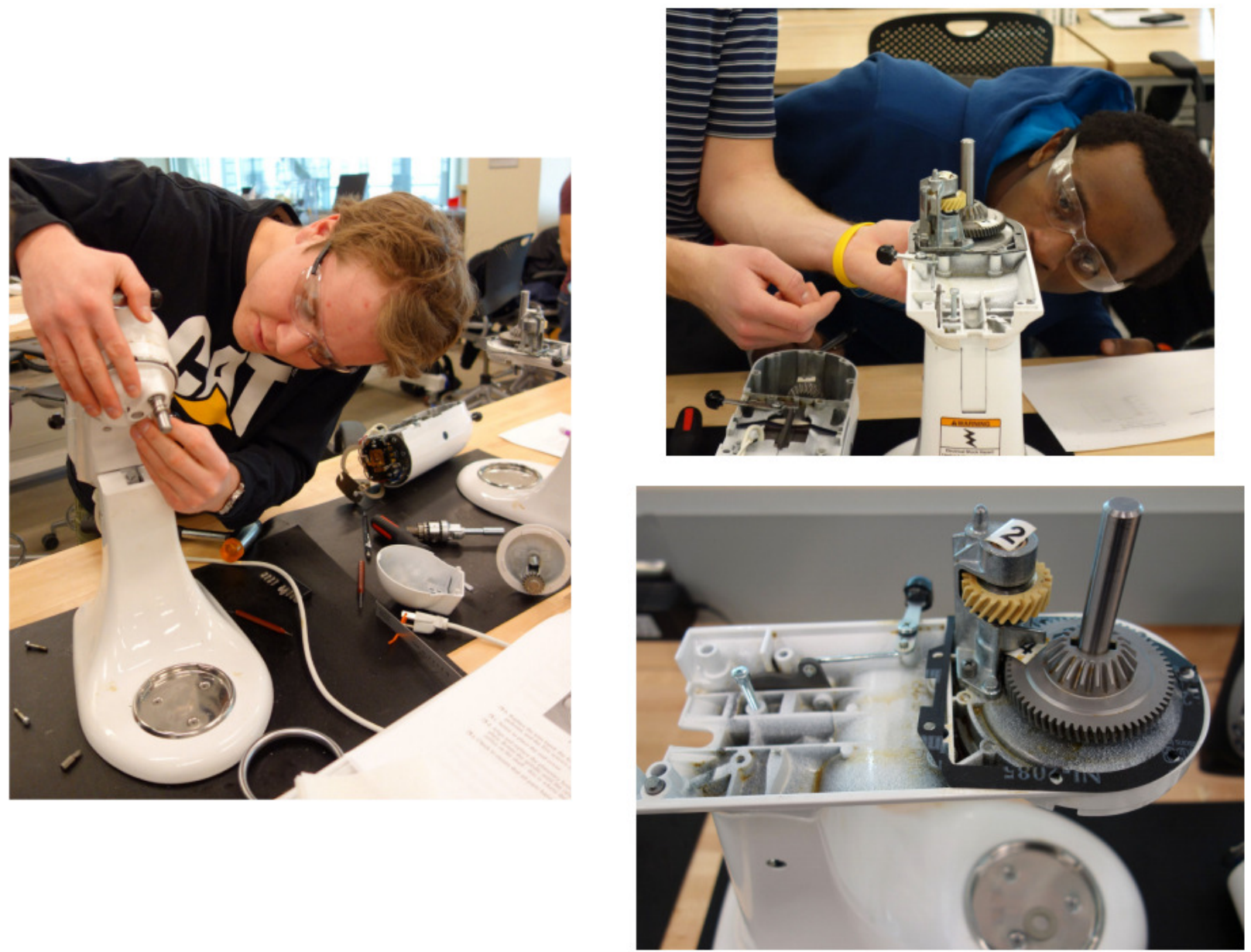

Figure 3: Kitchen mixer operation and gear design.

\section{Experiment 4: Gear Clock Design and Fabrication}

In this experiment (see Figure 4) the challenge is to design the gear mechanism for driving the minute and hour hands of a gear clock given a known yet arbitrary drive speed. Once students have arrived at a design and demonstrate that it will work (in CAD), they fabricate the gears via rapid prototyping (3D printing), are given a plastic mounting plate and fastener hardware, drill holes, and then assemble the clock. The power source is a motor attached to the input gear. Finally, the clock is tested for timing accuracy. Students face several real-world design questions, including how to minimize the number of gears and ensure clockwise rotation of the clock hands, how to assemble the clocks such that gears mesh appropriately, and how to explain timing errors. This experiment is conducted over two weeks due to the time needed for the detailed gear train design, 3D printing of gears, and for clock assembly. 

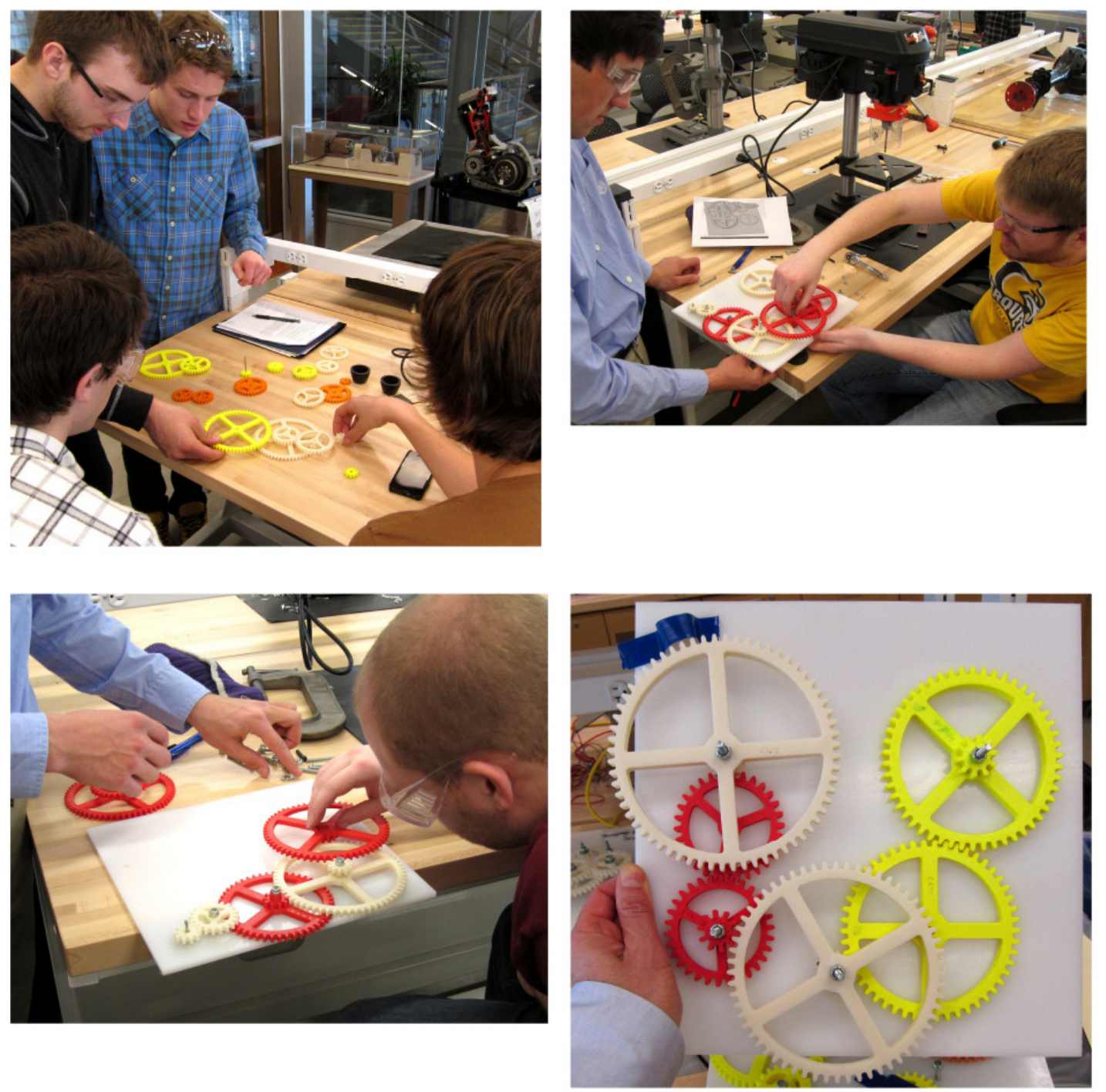

Figure 4: Gear clock design and fabrication.

\section{Discussion}

The four experiments as well as an accompanying laboratory manual were developed and refined over several years. As changes were made, the experiments were tested by senior undergraduate students for debugging purposes prior to deployment in the course. This testing aided in evaluating the feasibility of the experiments and in answering questions about the pedagogical value of the different activities. The students chosen for the testing had previously taken the "Design of Machine Elements" course and performed at a high level. Student testing was extremely valuable in identifying activities that needed improvement and items in the manual that needed revision. Based on their feedback, several changes were implemented to further promote discovery learning. Testing with former students is highly encouraged for anyone developing new laboratory experiments.

The revised experiments were implemented in the "Design of Machine Elements" course in the Spring 2014. Feedback from students and teaching assistants has confirmed the value of the 
experiments in engaging students in the analysis and design of gears and geared systems. Students became familiar with different types of gears, experimentally determined parameters of gears, analyzed, designed, and fabricated gears. From this, students gained an understanding of the applicability of gears to real-world problems while peaking interest.

\section{Feedback}

The intent of the experiments is to effectively enhance engineering students' awareness of gears and expand their knowledge and confidence in the use of gears in mechanical systems. The activities were adopted to help motivate student learning and foster interest in the topic of gears and gear systems.

Following the experiments in the Spring 2014, students were given an opportunity to submit feedback comments and to respond to a questionnaire specifically addressing the pedagogical value of the activities. In a voluntary survey of 77 students, 46 responded with significant input and $43(93.5 \%)$ of these students offered positive comments about the lab activities. Student responses included:

We learned much more than gears. I can't believe we had so much trouble with assembly of the clock due to problems with the center distances. It taught me a valuable lesson that a successful design is not just the right choice of mechanical components.

$\square \quad$ I learned more than I expected about a simple machine component. In past classes like dynamics we solved problems involving gears, but they were textbook problems. From this lab it makes much more sense how gears work and are used, so I got a deeper understanding.

I don't recall ever experimenting with gears. Seeing how they are used and even making gears with the $3 D$ printer made a significant impact on my understanding. This lab was valuable.

This lab was a great way for us to learn about gears and geared systems. I especially liked the clock part of the lab. I want more. Can we use the $3 D$ printer to make other machine components and build systems? That is the best way for us to learn.

$\square$ Gears are used in all kinds of machines, and it was very important for us to learn about gears in a lab setting where we could touch different gears, see gears in actual systems, and build a clock using gears. It was interesting and very realistic.

$\square$ The gear lab is my favorite so far. I really liked seeing all the systems, and I really liked designing the clock and then making it. Too bad it didn't work as well as our group hoped, but we were glad we did it. Any chance we can try it again, even if it doesn't change our grade. We want to make a working clock and even thought of more features we could add.

$\square$ The lab was effective and even fun. The questions really made us think. I could imagine spending more time and having more lab activities related to gears.

Students were also asked how the experiments could be made more effective and what additional activities would foster more learning, prompt further interest in machine design, and/or challenge students in meaningful ways. Specific comments included: 
The lab definitely motivated my learning. The only thing I can think of would be measuring the torque at the input and output shafts and confirming that the torque ratio gives the same as the train ratio based on gear diameters or number of teeth.

One idea would be to apply large enough loads to an input shaft to shear off teeth of gears in a gear-box. Students can then appreciate the value of a sacrificial gear near the end of a shaft so it can easily be replaced.

$\square$ The lab could include ways that gears are mounted to shafts, such as press-fits, set screws, etc. I know some of this was covered in the press-fits lab, but here you could measure how much torque can be applied before the gear slips on the shaft. This might require a new setup.

I would like to build something like the clock in each lab. It felt so good to see our clock working at the end. Could there be a way that the class could critique each design, and have the team defend their choices?

Could radial and tangential forces on shafts carrying gears be measured? That would connect the lab to the analyses in class and the book. It would also connect this lab to the bearing lab.

$\square$ Learning about gears has encouraged me to think about other mechanical components and how they are made. I would like to learn how real gears are machined. Seems like it would be very specialized manufacturing. Could students be asked to make real components, such as gears and bearings.

These ideas and suggestions are a source of new lab activities. Although some are easier than others to implement, many are worthwhile and reflect a deep understanding of gear concepts.

The experiments have been well received and based on student feedback the experiences have been meaningful. The goals of developing discovery learning activities as a means to increase interest in and understanding of gears and gear systems and encourage students to see real-world applications appear to have been met. Formative assessment will continue in the Spring 2015 semester following a similar lab with some modifications to the experiments described above.

\section{Conclusion}

This paper describes four experiments that focus on the characterization, design, and use of gears in mechanical systems. The experiments were created for a junior-level "Design of Machine Elements" course in the College of Engineering at Marquette University. Insights were provided into how well students became familiar with types and nomenclature of gears, as well as their understanding of the applicability of different gears to real world problems. The intent of the experiments is to enhance mechanical engineering students' awareness of gears and to expand their knowledge and confidence in the use of gears in machine and mechanism design. 


\section{Acknowledgments}

The experiments described in this paper were developed in concert with many talented students, whose contributions are deeply appreciated. Nelsy Hernandez, Stephen Jordan, Fernando Rodriguez Anton, and Dan Zachacki were especially instrumental and made many contributions.

\section{References}

1. Felder, R.M. and Brent, R., 2009, "Active Learning: An Introduction,” ASQ Higher Education Brief, 2(4).

2. Goldberg, J.R. and Nagurka, M.L., 2012, "Enhancing the Engineering Curriculum: Defining Discovery Learning at Marquette University," 42nd ASEE/IEEE Frontiers in Education Conference, Seattle, WA, October 3-6, pp. 405-410.

3. Prince, M., 2004, "Does Active Learning Work? A Review of the Research," Journal of Engineering Education, 93(3), pp. 223-231.

4. Cleverly, D., 2003, Implementing Inquiry Based Learning in Nursing, Taylor \& Francis, London, p.124.

5. Prince, M.J. and Felder, R.M., 2006, "Inductive Teaching and Learning Methods: Definitions, Comparisons, and Research Bases," Journal of Engineering Education, 95(2), pp. 123-138.

6. Prince, M.J. and Felder, R.M., 2007, "The Many Faces of Inductive Teaching and Learning," Journal of College Science Teaching, 36(5), pp. 14-20.

7. Nagurka, M. and Rodriguez-Anton, F., 2013, "Discovery Learning Experiments in a New Machine Design Laboratory," 2013 ASEE Annual Conference, Atlanta, GA, June 23-26.

8. Malak, P.W. and Nagurka, M., 2014, "Machine Design Experiments Using Mechanical Springs to Foster Discovery Learning,” 2014 ASEE Annual Conference, Indianapolis, IN, June 15-18. 